https://helda.helsinki.fi

\title{
Development of a tire-soil interaction model for agricultural tractors
}

\author{
Lajunen, Antti
}

2019

Lajunen , A 2019 , Development of a tire-soil interaction model for agricultural tractors . in LAND.TECHNIK AgEng 2019 : 77th Internatioal Conference on Agricultural Engineering : the forum for agricultural engineering innovations . LAND.TECHNIK AgEng, Hannover, Lower Saxony, Germany , 08/11/2019.

http://hdl.handle.net/10138/325583

cc_by

acceptedVersion

Downloaded from Helda, University of Helsinki institutional repository.

This is an electronic reprint of the original article.

This reprint may differ from the original in pagination and typographic detail.

Please cite the original version. 


\title{
Development of a tire-soil interaction model for agricultural tractors
}

\author{
Prof. A. Lajunen, University of Helsinki, Finland
}

\begin{abstract}
The objective of the presented research is to investigate and develop a high-fidelity model for tire-soil interaction in order to simulate accurately the tractive performance of agricultural vehicles. Accurate simulation of pneumatic tire - deformable soil interaction is fundamental for evaluating the mobility and tractive performance as well as for developing autonomous agricultural vehicles. Tire-soil interaction models integrated into a vehicle powertrain model allows investigating the important energy losses between driving axle and tractive performance because the tire-soil interface may cause over $50 \%$ of the total losses. A validated and accurate tire model is crucial for obtaining meaningful results about the tractive performance of agricultural vehicles that seldom have a fully suspended chassis. Recently, due to the increased computational power, complex physics-based methodologies that takes into account both tire flexibility and terrain deformation within a three-dimensional multibody system approach have been developed. In this research, a simulation environment was developed for an agricultural tractor-trailer combination by using a commercial simulation software. The tractive performance was analysed based on simulations carried out on uneven and soft soil terrain. Overall, the developed model was considered to be well-suitable for the evaluation of tractive performance of agricultural tractors in general level.
\end{abstract}

\section{Introduction}

Over the years, different types of vehicle-terrain and tire-soil interaction models have been developed for off-road vehicles. Most of these models rely on empirical, semi-empirical or physical approaches to quantifying the vehicle-terrain interaction [1]. Finite Element and Discrete Element Methods (DEM) combined with experimental measurements and analysis are commonly used for the investigation of vehicle-tire-soil interactions [2]. The different aspects of tire-soil interaction have been studied in the literature but less focus has been given for the soil mechanical properties and the properties influencing on the tire-soil interaction [3]. It is also important to understand and identify the soil physical properties (such as soil texture, structure, moisture content, density, porosity, etc.) in order to accurately model the tire-soil interaction. Soil mechanical properties and conditions influence 
significantly on tire and tractive performance of off-road wheeled vehicles [3]. However, many tire-soil interaction models have been developed without measuring soil properties [4]. Some alternative methods for model validation and defining of tire dynamic parameters have been proposed such as the use of experimental data sets without using conventional test equipment [5] or rigorous statistical methods [6]. Despite of the research developments, there is a lack of deformable terrain models to estimate accurately the tractive performance of agricultural vehicles based on tire-soil interaction simulation [7]. Another challenge is that the available tire-soil interaction models are often limited by several characteristics for their applicability to vehicle dynamics simulations [8]. The particular characteristics of agricultural tires were studied by Witzel in [10] and an entirely new multi-spoke tire model was developed. The model validation showed a very high level of accuracy however, the soil characterization was not included [11]. Recently, due to the increased computational power, complex physics-based methodologies that takes into account both tire flexibility and terrain deformation within a three-dimensional multibody system approach have been developed [7], [12].

The objective of the presented research is to investigate already developed tire-soil interaction models and analyze their performance. The studied physical model developed in the AMESim simulation software presents a full tractor-trailer model with a specific focus on tire modeling. The tire model is developed to have a minimum amount of parameters therefore there are some weaknesses e.g. the tread pattern of the tire has been neglected. However, the simulation of complex phenomena often requires model simplifications. The studied model will be further developed by implementing more accurate methods for the calculation of tire-soil contact and by taking into account different tire tread patterns and soil properties. The tire-soil interaction model development that has been done by the University of Wisconsin-Madison will be studied. They have developed a tool called Chrono which is a multi-physics modelling and simulation infrastructure based on a platform-independent, open-source design [12]. In a larger context, the aim is to create a virtual simulation environment for agricultural vehicles. Accurately modelled vehicle-tire-soil interaction allows testing new technological solutions and autonomous operations in a virtual environment.

\section{Modelling}

The simulation software AMESim was used as the model development environment. AMESim is a multi-domain software allowing to link different physics domains and provides a detail approach of modelling vehicle systems. The software provides an extensive 
component library for powertrains and vehicle dynamics. The simulation model that was used in this research corresponds to a tractor-trailer combination operating on a soft soil surface. The model consist of the following main parts:

1) 3-dimensional mechanism of the tractor trailer

2) Simplified powertrain

3) Chassis models for three axles

4) Tire kinematics and soil-interaction

5) Environment and tractor control

\section{3-dimensional mechanism of the tractor trailer}

The tractor-trailer body mechanism is modelled with a multibody mechanism composed of two solids which are linked by an ideal spherical joint. The trailer weight is transferred to tractor rear wheels through hitch point and axle positions. The system has 9 degrees of freedom and both mechanical bodies have input for force and torque. Figure 1 presents the animated illustration of the tractor-trailer combination.

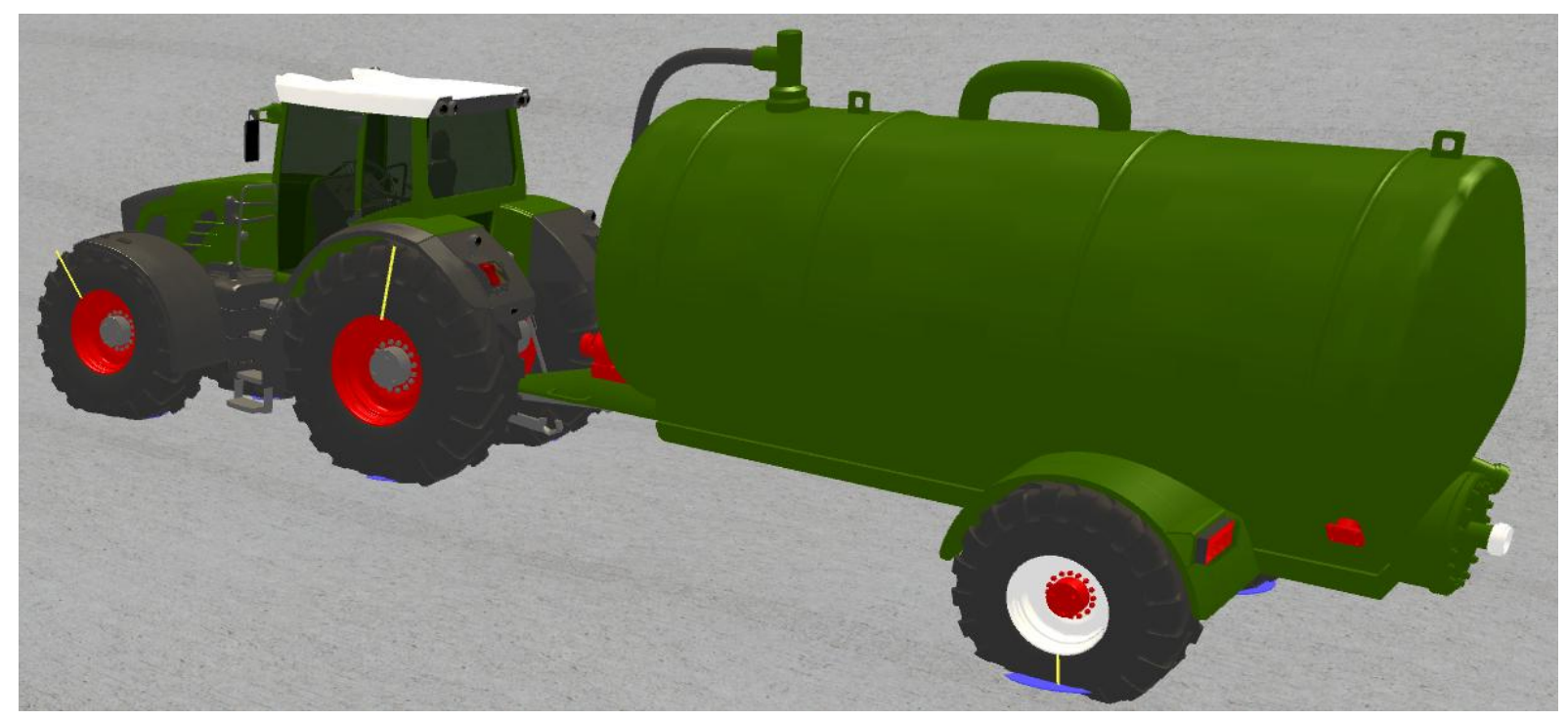

Fig. 1: Illustration of the simulation model.

\section{Simplified powertrain}

The powertrain model consist of a reduction gear and three differential gears that deliver the engine torque to front and rear axles of the tractor. For faster simulation, no engine and gearbox was modelled. Each differential gear has adjustable limited slip and the input power and torque are limited. Figure 2 presents the differential gear models; the upper differential splits the torque between the front and rear axle. 


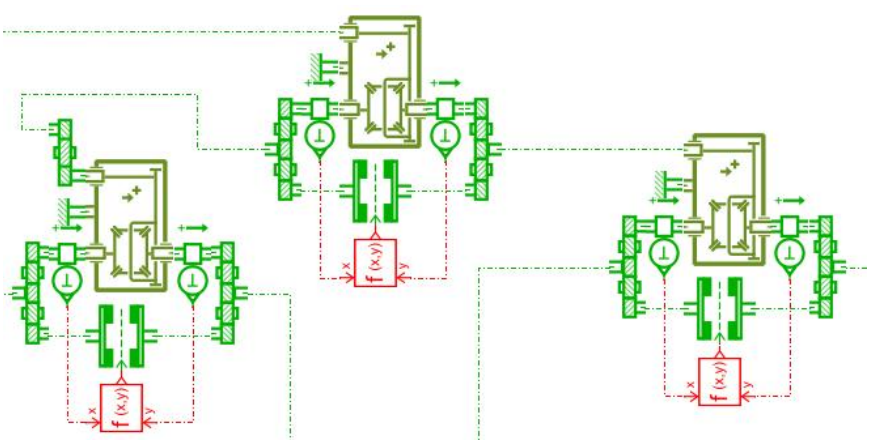

Fig. 2: Differential gear models.

\section{Chassis models for three axles}

The chassis were modelled with a specific block that contains the kinematics of the left and right wheel suspensions as presented in Figure $3 a$. Figure $3 \mathrm{~b}$ presents the wheel suspension model inside of the chassis model. The front axle has steering system and a freely oscillating axle with end stops. The axles may have different tracks and different tire size.

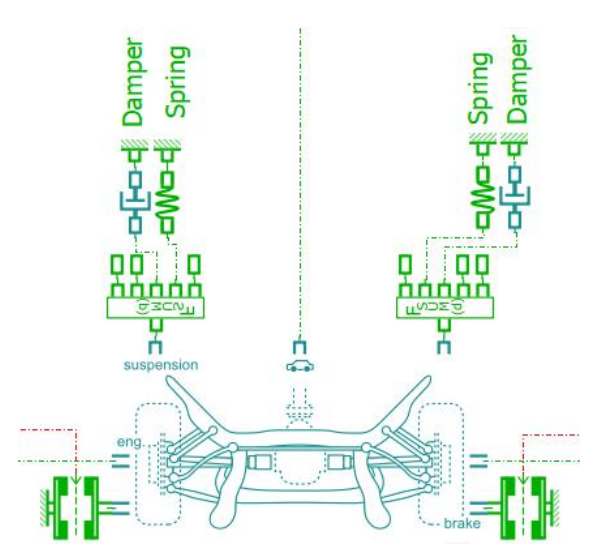

Fig. 3a: Tractor rear chassis model.

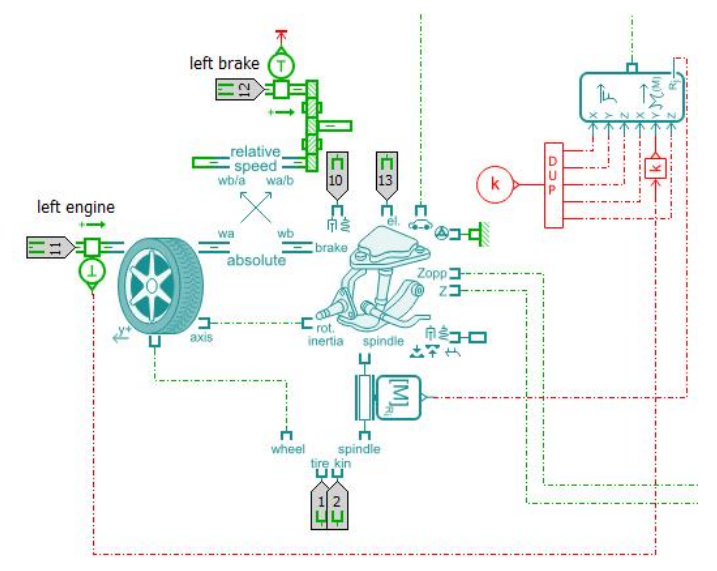

Fig. 3b: Wheel suspension model.

\section{Tire kinematics and soil-interaction}

The tire kinematic model, presented in Figure 4a, computes all kinematic elements of centre of tire-ground contact area. This model can be seen as the interface between the vehicle model and global tire model. The tire belt model (lower part in Figure 4a) allows the computation of characteristic inputs of the tire model. The tire model (upper part in Figure $4 b$ ) generates the contact forces at the tire-soil interface. The calculation is based on a modified Brixius-model for the longitudinal behaviour, and a Dugoff-model for the lateral aspects. The emphasis is on modelling the resulting rolling resistance and tractive capacity of the tire. The road grip model (middle part in Figure $4 b$ ) act as a connection between the tire and road 
model. The ground block (lower part in Figure 4b) contacts the tire on the road and outputs the height, normal and apparent vertical road speed.

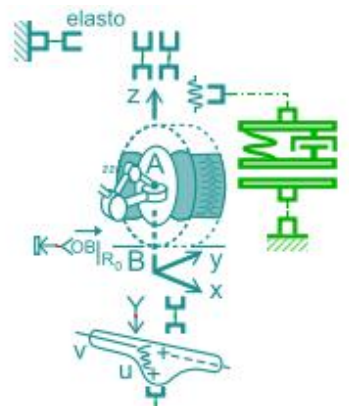

Fig. 4a: Tire kinematic model.

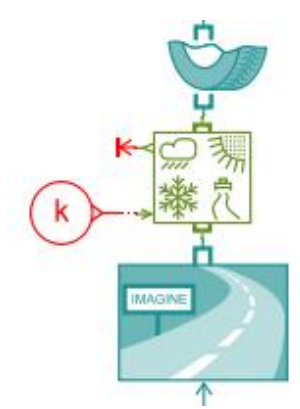

Fig. 4b: Tire and road grip model.

\section{Environment and tractor control}

The example environment describes large scale features such as uphill section and side slopes as well as medium scales that rock the vehicle and creates varying uneven load on the wheels. The model includes a driver model that actuates the throttle, braking and steering based on a predefined mission profile and target speed. The mission profile has tight turns that result in different rotating speeds between left and right wheels.

\section{Model parameters}

The simulation model has numerous parameters therefore only the key influencing parameters are described here. The tractor parameters refers to a typical agricultural tractor having engine power of $175 \mathrm{~kW}$. Trailer load was $60 \%$ from the maximum load resulting to the total weight of $10000 \mathrm{~kg}$ for the trailer.

Table 1: Tractor and trailer parameters

\begin{tabular}{|l|c|}
\hline Parameter & Value \\
\hline Engine maximum power $(\mathrm{kW})$ & 175 \\
\hline Engine maximum torque $(\mathrm{Nm})$ & 719 \\
\hline Tractor weight $(\mathrm{kg})$ & 8000 \\
\hline Trailer weight $(\mathrm{kg})$ & $4000 \ldots 14000$ \\
\hline
\end{tabular}

Table 2: Tire parameters

\begin{tabular}{|l|c|c|c|}
\hline Parameter & Front axle & Rear axle & Trailer axle \\
\hline Free radius of tires $(\mathrm{m})$ & 0.99 & 1.197 & 0.862 \\
\hline Rolling radius of tires $(\mathrm{m})$ & 0.97 & 1.18 & 0.84 \\
\hline Vertical tire stiffness $(\mathrm{N} / \mathrm{m})$ & 200000 & 400000 & 300000 \\
\hline Vertical tire damping $(\mathrm{N} /(\mathrm{m} / \mathrm{s}))$ & 10000 & 20000 & 7500 \\
\hline
\end{tabular}




\section{Simulation results}

Simulations were carried out with different parameter sets for evaluating the model performance and the tractive performance of the modelled tractor-trailer combination. The presented results include two reference simulations; 1) soil cone index $(\mathrm{Cl})=900 \mathrm{kPa}$, and 2) soil $\mathrm{Cl}=450 \mathrm{kPa}$. Figure 5 presents the tractor-trailer speed and trajectory for both simulations. The results clearly show that the softer soil reduced the mobility of the tractortrailer combination especially in the uphill parts of the trajectory.
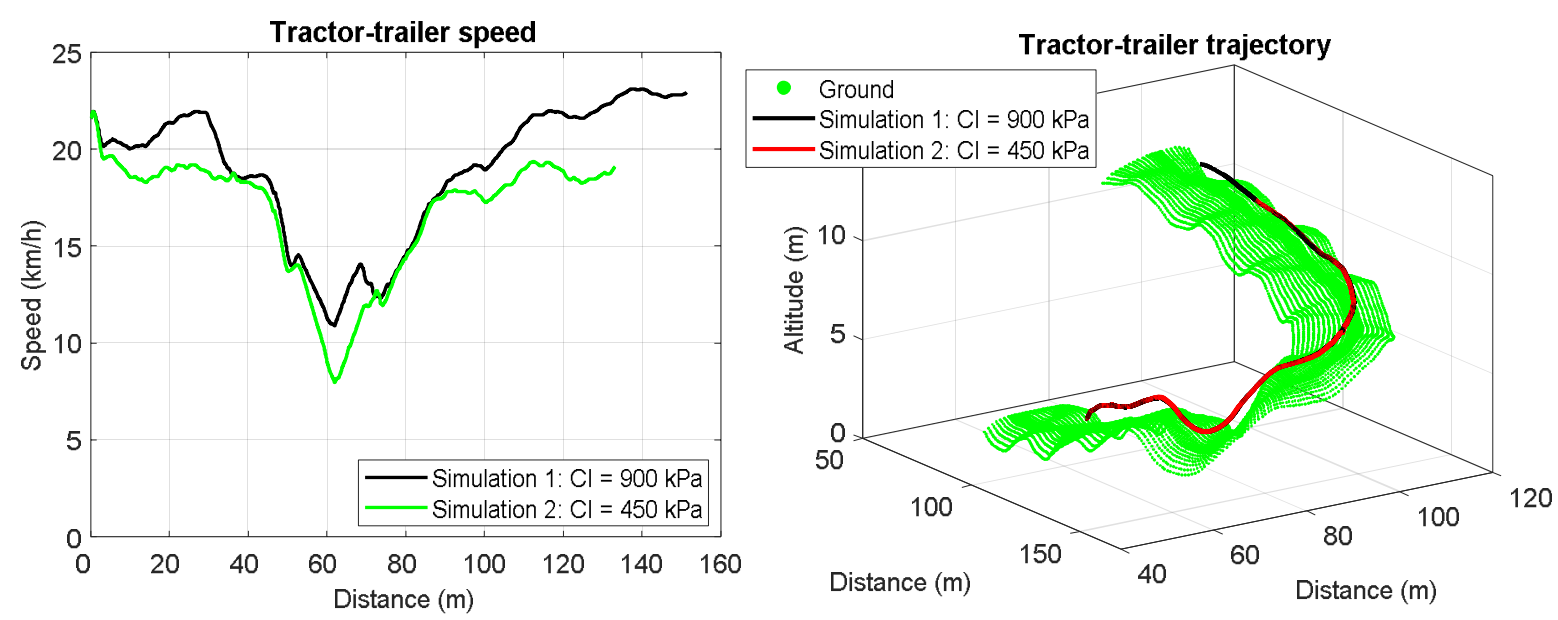

Fig. 5: Driving speed and trajectory.

Tire forces were observed from the simulations results. The longitudinal and vertical tire forces of tractor are presented in Figure 6 and 7, respectively. Naturally, the rear wheel forces are higher than the forces in the front wheels. The influence of the short downhill part and the steep uphill can be clearly observed from the results starting in 40 meter point until to 70 meters as distance travelled. The oscillating front axle lowers the peak amplitudes of the vertical force whereas there is vertical force transfer from left to right all the time at the rear axle due to the uneven ground surface.
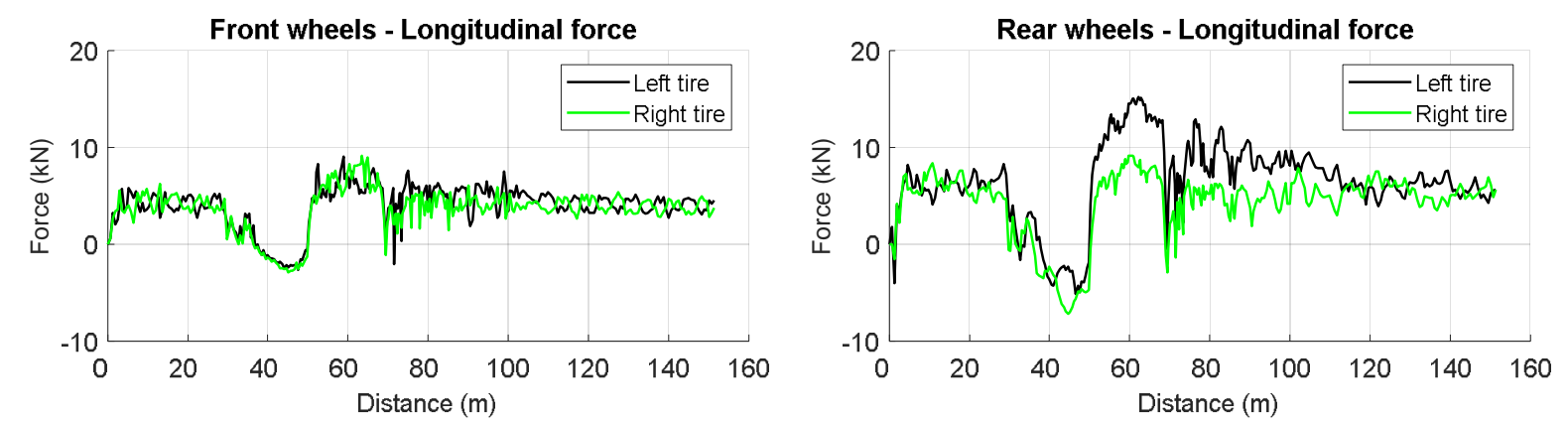

Fig. 6: Tire longitudinal forces, $\mathrm{Cl}=900 \mathrm{kPa}$. 

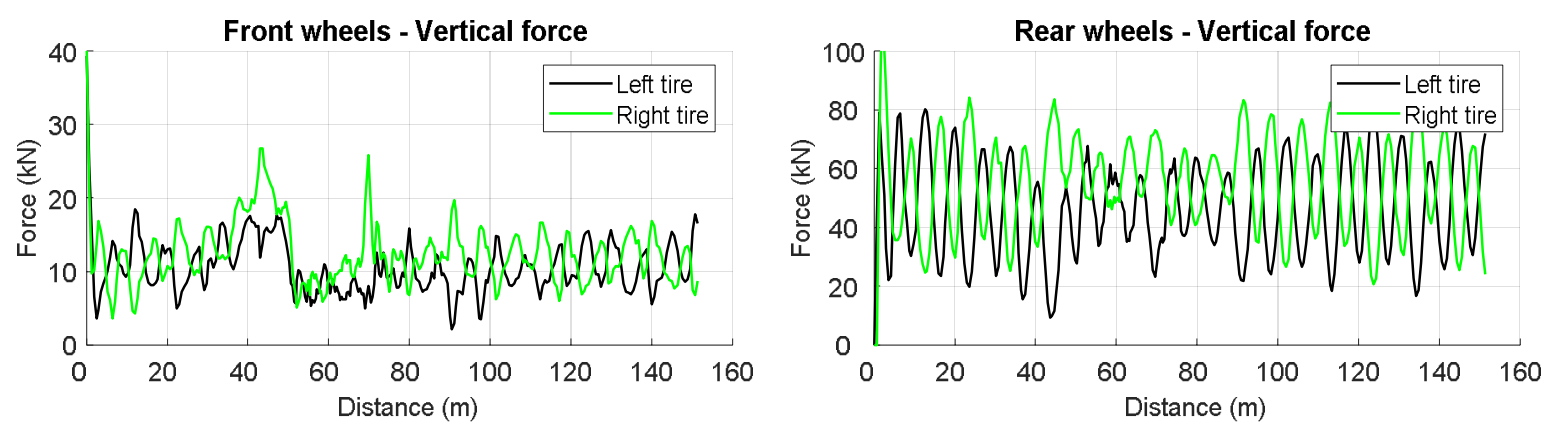

Fig. 7: Tire vertical forces, $\mathrm{Cl}=900 \mathrm{kPa}$.

Figure 8 shows the tractive efficiency and longitudinal slip of the tractor wheels. In the steep uphill, the weight transfer lightens the front axle and the longitudinal slip increases drastically. This directly influence on the tractive efficiency which is above $80 \%$ in more steady driving situations but drops significantly in the uphill. The weight transfer from the left to the right wheel at the rear axle have a significant effect on the tractive efficiency but much less impact on the longitudinal slip. The right turning (from $80 \mathrm{~m}$ until $120 \mathrm{~m}$ ) causes the outer right rear tire having lower tractive efficiency during turning.
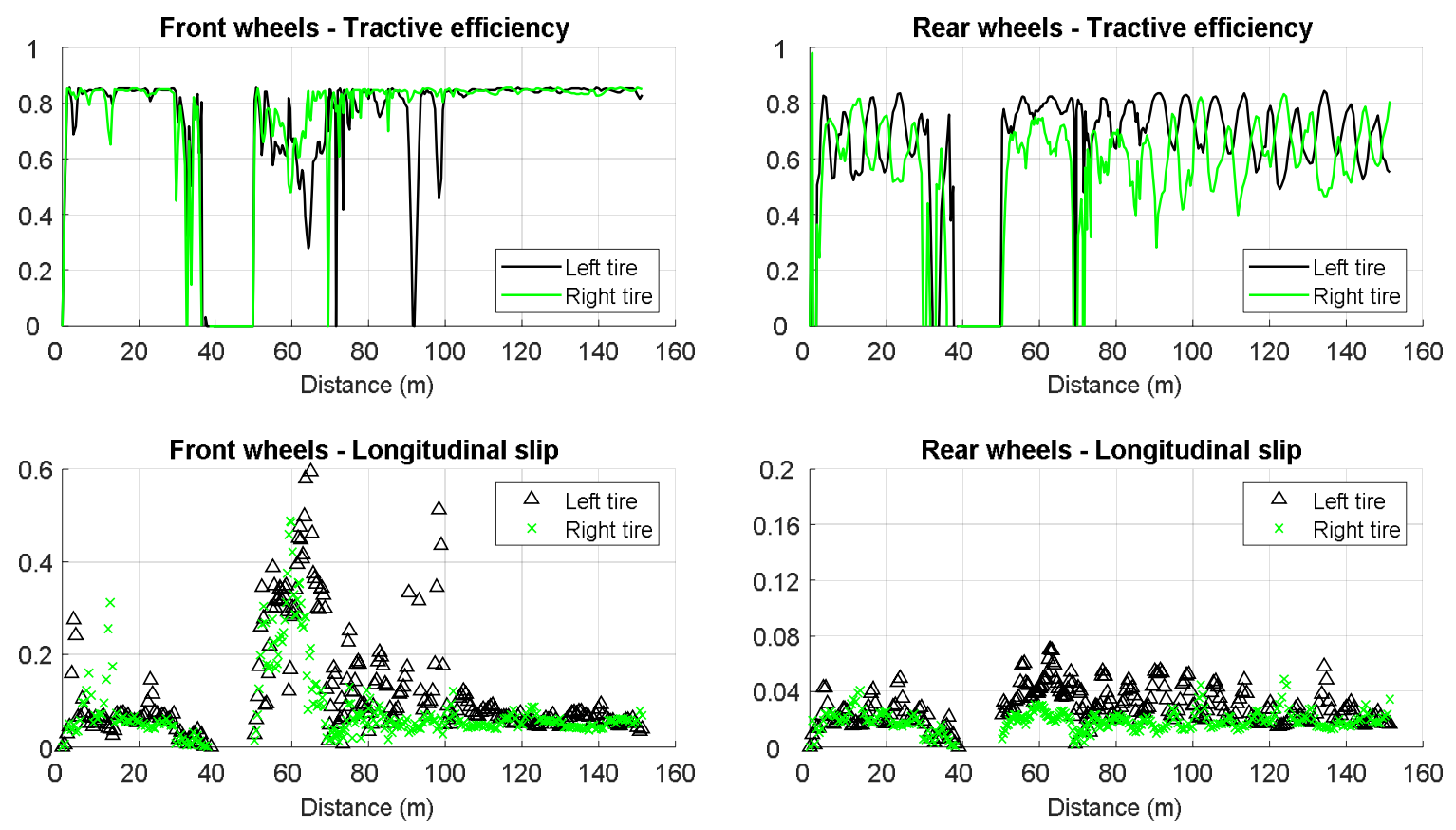

Figure 8: Tractive efficiency and longitudinal slip, $\mathrm{Cl}=900 \mathrm{kPa}$. 


\section{Discussion and conclusions}

This research presented an evaluation of a tire-soil interaction model to simulate agricultural tractor tractive performance on soft soil surfaces. The multi-physics model included simplified powertrain and detail description of chassis, tire kinematics and tire-soil contact. The simulations on uneven and irregular soft terrain illustrated well the model performance and some shortcomings. Overall, the developed model was considered to be well-suitable for the evaluation of tractive performance of agricultural tractors in general level. More precise estimations about vehicle mobility on different types of soft terrains would require more model development especially in terms of tire-soil interaction level.

The developed simulation environment provides a versatile approach for evaluation of offroad vehicles. The future research work will focus on the development of high-fidelity tire-soil interaction model that can be implemented in the present simulation environment. Experimental measurements are foreseen in the future research for the model validation.

\section{Bibliography}

[1] Taheri, Sh., Sandu, C., Taheri, S., Pinto, E. and Gorsich, D.: A technical survey on Terramechanics models for tire-terrain interaction used in modeling and simulation of wheeled vehicles. Journal of Terramechanics 57 (2015) pp. 1-22

[2] Ani, O.A., Uzoejinwa, B.B., Ezeama, A.O., Onwualu, A.P., Ugwua, S.N. and Ohagwu, C. J.: Overview of soil-machine interaction studies in soil bins. Soil and Tillage Research 175 (2018) pp. 13-27

[3] Lyasko, M.I.: How to calculate the effect of soil conditions on tractive performance. Journal of Terramechanics 47 (2010) 6 pp. 423-445

[4] Ekinci, S., Çarman, K. and Kahramanli, H.: Investigation and modeling of the tractive performance of radial tires. Energy 93 (2015) 2 pp. 1953-1963

[5] Ospina, R. and Noguchi, N.: Alternative method to model an agricultural vehicle's tire parameters. Engineering in Agriculture, Environment and Food 11 (2018) pp. 9-18

[6] Lee, J.H. and Gard, K.: Vehicle-soil interaction: Testing, modelling, calibration and validation. Journal of Terramechanics 52 (2014) pp. 9-21

[7] Melanz, D., Jayakumar, P. and Negrut, D.: Experimental validation of a differential variational inequality based approach for handling friction and contact in vehicle/granular-terrain interaction. Journal of Terramechanics 65 (2016) pp. 1-13

[8] Chan, B.: Development of an Off-Road Capable Tire Model for Vehicle Dynamics Simulations, Doctoral Dissertation - Virginia Polytechnic Institute and State University 2008 
[9] Roth. J. and Darr, M.J.: Measurement of Normal Stresses at the Soil-Tire Interface. Agricultural and Biosystems Engineering Publications - Transactions of the ASABE 55 (2012) pp. 325-331

[10] Witzel, P.: The Hohenheim Tyre Model: A validated approach for the simulation of high volume tyres - Part I: Model structure and parameterisation. Journal of Terramechanics 75 (2018) pp. 3-14

[11] Witzel, P.: The Hohenheim Tyre Model: A validated approach for the simulation of high volume tyres - Part II: Validation. Journal of Terramechanics 75 (2018) pp. 15-24

[12] Recuero, A., Serban, R., Peterson, B., Sugiyama, H., Jayakumar, P. and Negrut, D.: A high-fidelity approach for vehicle mobility simulation: Nonlinear finite element tires operating on granular material. Journal of Terramechanics 72 (2017) pp. 39-54 